\title{
Estratégias de Inbound Marketing em Uma Indústria 3.0
}

Inbound Marketing Strategies in An Industry 3.0

\section{Resumo}

A difusão entre a internet e o marketing permitiu as empresas explorarem novos campos de atuação frente ao mercado, assim o marketing digital surgiu para facilitar o processo de compra e vendas, entre as ferramentas utilizadas por este, está o inbound marketing. O objetivo do presente estudo foi propor uma discussão sobre o uso e aplicação de estratégias de inbound marketing e verificar a aplicação desta nova filosofia de marketing por uma indústria 3.0. Desta forma, foi realizado um estudo de caso através de pesquisa survey, para se obter informações sobre a aplicação do inbound marketing na mesma, bem como as ferramentas utilizadas. Os resultados do estudo demonstraram que as estratégias do google adwords, bem como estratégias de marketing de relacionamento direto são os meios que mais fidelizam os clientes. Dentre as principais dificuldades foram mencionados a preocupação na geração de conteúdo de qualidade, a falta de recursos para as áreas de marketing, bem como para a implementação de estratégias mercadológicas e a compreensão da complexibilidade dos mercados-alvos.

Palavras-chave: Inbound marketing. Marketing. Marketing digital. Marketing de relacionamento.

\section{Abstract}

The diffusion between the internet and marketing allowed companies to explore new fields of action in front of the market, so digital marketing emerged to facilitate the process of buying and selling, among the tools used by this is inboundd marketing. The objective of the present study was to propose a discussion about the use and application of inbound marketing strategies and to verify the application of this new marketing philosophy by an industry 3.0. In this way, a case study was conducted through survey research, to obtain information about the application of inbound marketing in the same, as well as the tools used. The results of the study demonstrated that google adwords strategies as well as direct relationship marketing strategies are the means that most loyal customers. Among the main difficulties mentioned were the concern in the generation of quality content, the lack of resources for the marketing areas, as well as for the implementation of marketing strategies and the understanding of the complexity of the target markets.

Keywords:

Rod. Raposo Tavares, km, 92.5, Sorocaba-SP, CEP 18023-000, sueli.sa@terra.com.br ALMEIDA, S. S. Estratégias de Inbound Marketing em Uma Indústria 3.O. GEPROS. Gestão da Produção, Operações e Sistemas, v. 14, n.3, p. 7 - 13, 2019.

DOI: 10.15675/gepros.v14i3.2527 


\section{INTRODUÇÃO}

Com certeza, hoje o caminho para a nossa indústria prosperar é a inovação de seus produtos e serviços. Uma visão de futuro da Indústria 4.0 prevê-se que, nos anos 2020, o maior "grupo de usuários" da internet serão produtos inteligentes e conectados (algo em torno de 24 bilhões de dispositivos). Segundo Turchi (2018), mais da metade da população brasileira (cerca de 139 milhões de pessoas) está presente na web. São pessoas se relacionando, produzindo e disseminando conteúdo, usando diversos entretenimentos online ou buscando informações e promoções pela internet. E com o desenvolvimento da internet, o ambiente digital passou a ser visto pelo setor corporativo como um terreno fértil a ser explorado e como forma de imprimir maior agilidade aos negócios. Inclui-se aqui aspectos importantes para os consumidores, tais como: os produtos inteligentes serão identificados de forma única e poderão ser localizados a qualquer momento, desde quando ainda estão sendo fabricados até o fim da sua vida útil; será possível incorporar características específicas de cada consumidor individual em todas as fases, do projeto à reciclagem ou disposição final; será possível incorporar mudanças de última hora, inclusive durante o processo de fabricação. Assim, nesse novo modelo, a entrega do produto não é o fim, mas, o início do processo de intensa interação entre produtor e consumidor.

A luz de todas essas revoluções trazidas pela internet percebe-se mudanças profundas no comportamento das pessoas, tirando-as de um estado de passividade e tornando-as mais críticas, exigentes e ativas junto às marcas. E também está exigindo das empresas uma postura de atualização e inovação permanentes, podendo-se afirmar que há realmente mudanças que alteram o conhecimento que as empresas tinham de seus consumidores e sobre qual a melhor forma de alcançá-los. Dessa maneira, o outbound marketing, que tem como objetivo obter a atenção de potenciais clientes unicamente por meio da publicidade (PIEDRAHITA, 2015), precisou ser revisto, pois não compreende de forma eficaz o indivíduo moderno. Entender o indivíduo passou a ser uma difícil tarefa e, para isso, outras formas de se fazer o marketing tiveram de ser pensadas, como o inbound marketing.

O inbound marketing, também chamado de marketing de atração, para Burnes (2015, apud OLIVEIRA, 2015, p. 60), o inbound marketing rompe com os antigos conceitos de marketing e apresenta uma nova visão que se baseia em ganhar o interesse das pessoas e fazer com que os potenciais clientes procurem e encontrem as empresas.

No entanto, percebe-se que o domínio sobre o assunto no cenário nacional é escasso, e ainda pouco se utiliza dessa nova forma de se fazer o marketing pelas empresas. Assim, a presente pesquisa tem o objetivo de propor a discussão sobre o uso e aplicação de estratégias de inbound marketing e verificar a aplicação desta nova filosofia de marketing pelas empresas industriais. 


\section{REFERENCIAL TEÓRICO}

\subsection{Marketing: da evolução à conceituação}

De acordo com a American Marketing Association - AMA (2013), o marketing é definido como a "atividade, conjunto de instituições e processos para criar, comunicar, distribuir e negociar ofertas que tenham valor para os consumidores, clientes, parceiros e sociedade em geral".

Com o passar dos anos, desde a sua primeira conceituação, o marketing vem evoluindo de forma intensa. Para Kotler, Kartajaya e Setiawan (2010, p. 3), o marketing divide-se em 4 estágios: Marketing 1.0 (foco no produto); 2.0 (foco no consumidor); 3.0 (foco nos valores) e 4.0 (foco nos sentimentos humanos). O marketing 1.0 surge "durante a era industrial - quando a principal tecnologia se relacionava a equipamentos industriais, o marketing dizia respeito a vender produtos da fábrica a todos que quisessem comprá-los”. Já o marketing 2.0 “surgiu na atual era da informação - orientado para o consumidor, sendo que o profissional da área deve segmentar o mercado e desenvolver um produto superior para um mercado-alvo específico" (KOTLER; KARTAJAYA; SETIAWAN, 2010, p. 4). O marketing 3.0 tem a ideia de satisfazer os consumidores, que são pessoas complexas, com necessidades que jamais devem ser deixadas de lado. Além disso, completa "o marketing emocional com o marketing do espírito humano" (KOTLER; KARTAJAYA; SETIAWAN, 2010, p. 5).

Segundo Jara, Parra e Skarmeta (2012), o marketing 4.0 continua concentrando-se nas necessidades e desejos das duas primeiras gerações do marketing, bem como satisfaz os desejos, ansiedades, criatividade e valores do marketing 3.0. Porém, trata-se de estratégias que tornam as pessoas mais conscientes dos valores e das ações sociais da marca, ou seja, os recursos oferecidos devem ser condizentes aos valores defendidos pela organização.

\subsection{Marketing: da evolução à conceituação}

Diante da evolução tecnológica e a necessidade de expansão das empresas, viu-se a possibilidade de unificar as duas áreas (computacional e marketing), surgindo, então, o conceito de marketing digital, sendo este aplicado para facilitar o processo de compra e venda de produtos/serviços.

Segundo Vaz (2010, p. 54), o advento da era da informação criou um novo tipo de consumidor, com diferentes perspectivas, desafios e oportunidades "para aqueles que souberem como funciona essa nova máquina”. O autor ainda salienta que um novo caminho deverá ser percorrido pelas empresas que desejam sucesso em sua trajetória, dando o codinome de "máquina" ao que se refere ao marketing digital.

Para Keller e Machado (2006, apud AGUIAR; BASTOS, 2016), "os profissionais de marketing vêm abandonando as práticas de marketing massivas que fortaleceram marcas poderosas nas décadas de 50 até 70 para implementar novas abordagens". 
Assim, o emprego do marketing digital desde então foi estendido aos demais mercados, com objetivos diferentes, não mais limitados à compra e venda de produtos pela internet, mas sim como uma ferramenta essencial para o desenvolvimento de novas estratégias para se chegar ao indivíduo.

Vértice (2010 apud OLIVEIRA, 2015, p. 56), salienta que "o marketing digital utiliza instrumentos que lhe permitem manter uma relação contínua entre a empresa e os seus clientes e este reúne características próprias do marketing direto".

Segundo Endeavor (2018) para que este novo instrumento seja utilizado de modo efetivo, são necessários cinco requisitos básicos:

I. Atração: Produção de conteúdo, otimização de conteúdo e compra de mídia.

II. Conversão: Geração de leads, oferta, landing page e promoção.

III. Relacionamento: Mídias Sociais, e-mail marketing e nutrição de leads.

IV. Venda: Qualificação de leads, alinhamento entre marketing e vendas.

V. Análise: Análise de dados.

Dentro do marketing digital, existem seis pilares fundamentais para seu pleno funcionamento, a saber:

a. Mídia Online: compreende os meios de comunicação que se utilizam da linguagem binária da informática (PERNISA JR, 2002).

b. SEO (Search Engine Optimization): traduzido como Otimização de Motores de Busca, trata-se de um conjunto de técnicas que possuem o objetivo de melhorar o posicionamento de páginas nos mecanismos de buscas online. Dessa forma, quando o usuário realiza uma pesquisa pela palavra-chave, o $S E O$ faz com que uma ou algumas páginas do seu website sejam encontradas e apareçam entre os primeiros resultados das buscas orgânicas, ou seja, excluindo-se os anúncios pagos (RICOTA, 2007).

c. Social (Mídia Social): definida como um conjunto de dinâmicas que permite a criação de conteúdo, difusão e trocas de informações, dentro de grupos sociais em plataformas online, ou seja, as chamadas redes sociais. Estas ações são produzidas pela interação de seus usuários por meio da propagação de informações, compartilhamento de conteúdo, e demais mobilizações sociais realizadas em meio eletrônico (RECUERO, 2010).

d. Marketing de Conteúdo: trata-se de um conjunto de ações em marketing ou negócios que visa criação e distribuição de conteúdo para atrair, conquistar e envolver o público-alvo com a sua marca, sempre com a intenção de gerar lucro (PULIZZI, 2016).

e. Web Analytics (Web Análise): consiste no monitoramento de ações da marca na internet, por meio da coleta de dados estatísticos, medição e análise quantitativa, para otimizar os websites e as iniciativas de marketing na web (WEB ANALYTICS ASSOCIATION, 2010 apud TELMA, 2011).

f. Inbound Marketing: segundo Burnes (2015, apud OLIVEIRA, 2015), são ações estratégicas de marketing contrária ao outbound marketing, tendo como objetivo fazer com que o cliente, volunta- 
riamente, ao buscar informações importantes ou respostas às suas perguntas, seja capaz de encontrar a marca por meio de mecanismos de busca online ou offline.

\subsection{Inbound Marketing}

Antes de tratar especificamente do inbound marketing, importante se faz conceituar outbound marketing. Segundo Piedrahita (2015), o outbound marketing "se baseia em conseguir a atenção de potenciais clientes através de publicidade, tentando conduzir os mesmos a realizar determinada ação". Ou seja, o outbound marketing pode ser entendido como estratégias tradicionais de marketing, sendo: publicações em revistas e jornais, comerciais de rádio e televisão, outdoor, banners em sites ou blogs, etc. Neste tipo de estratégia, a empresa expõe seus possíveis clientes a formas de propagandas que, muitas vezes, podem ser interpretadas como invasivas e indesejadas. A vantagem desse tipo de estratégia está no fato de que o profissional de marketing está no controle de todas as variáveis da mensagem enviada ao mercado. Por outro lado, exige que a empresa conheça intimamente seu público-alvo, pois a mensagem deverá chegar até ele e ser corretamente compreendida.

Já no inbound marketing, as estratégias devem ser focadas nos interesses dos consumidores de forma individual, apresentando alternativas e deixando com que eles procurem e se envolvam com a marca. Dessa forma, é deixado seduzir-se, acontecendo o engajamento do cliente com a marca, ao passo que quem fornece a informação torna-se referência no assunto.

O inbound marketing tem a intenção de posicionar a empresa como um especialista sobre o assunto, oferecendo informação ao seu público-alvo, fazendo com que seus mercados se dirijam até a marca para consumir o que ela tem para oferecer.

O conceito de inbound marketing foi concebido em 2005 nos EUA, sendo popularmente difundido em 2009 após a publicação do livro "Inbound Marketing: seja encontrado usando o Google, a mídia social e os blogs", de Brian Halligan e Dharmesh Shah (SFREDO, 2017).

De acordo com Sfredo (2017 apud HALLIGAN; SHAH, 2010), o inbound marketing consiste em ser encontrado online por meio de mecanismos de buscas e em redes sociais, como Facebook, Twitter e Youtube, que milhões de pessoas usam diariamente para encontrar respostas. No entanto, assim como no outbound marketing, o inbound pode ser usado também offline, quando empresas que, mesmo através de meios tradicionais, como os encartes, tentam atrair os clientes para si, sem forçá-los a interagir com a marca. Conteúdos "faça você mesmo" em impressos é exemplos dessa aplicação.

Para Assad (2016), o inbound tem o propósito de transformar usuários em contatos qualificados (também chamados de leads), e de forma espontânea converter leads em clientes, e estes em divulgadores da marca. 
A HubSpot, plataforma criada por Halligan e Shah para apoiar a ideia de inbound marketing, cunhada em 2005, tem uma metodologia dividida em quatro fases (HUBSPOT, 2018), caracterizando o "funil de vendas" sendo:

1. Atração (Attract): desenvolvimento de conteúdo na internet que atrai cada vez mais visitante até a sua marca/site, utilizando de redes sociais, blogs, vídeos, etc. Dessa forma, converte-se "estranhos (strangers) em visitantes (visitors)".

2. Conversão (Convert): uma vez que captada a atenção de estranhos para a marca, é necessário transformá-los em leads (contatos qualificados) para conhecê-los melhor, ou seja, abrir canais de contato por meio de formulários, encontros, mensagens ou CRM - Customer Relationship Management (Gestão de Relacionamento com o Cliente). Aqui têm início do processo de vendas propriamente dito.

3. Fechamento (Close): esse processo é focado em leads que, possivelmente, irão se tornar clientes (customers), ou seja, nos indivíduos que estão mais propensos a finalizar o processo de compra/ venda. Nesta etapa, deve-se investir mais em relacionamento, mostrando-se sempre presente, visando a manutenção de suas relações.

4. Encantar (Delight): o processo do funil de vendas, diferentemente do que se imagina, não acaba na fase vendas, pois o inbound marketing proporciona uma excepcional experiência para seus clientes. Desta forma, o encantamento é a fase mais importante para a marca, fazendo com que os clientes se tornem defensores (promoters) e advoguem a favor da marca, indicando-a para seus conhecidos. Aqui se pode investir mais em relacionamentos e pesquisas, para tornar os clientes mais engajados com a marca, propagando-a pelo mercado.

\section{REFERENCIAL TEÓRICO}

\subsection{Objeto de Estudo}

Para o desenvolvimento do presente estudo foi utilizado pesquisa bibliográfica e estudo de caso de marketing digital junto à uma indústria brasileira metalúrgica, de médio porte, localizada no interior de São Paulo, cuja fundação foi em 1957, portanto, uma empresa de mais de 60 anos atuando no mercado de rolamentos industriais. Seu público-alvo são distribuidores, revendas, empresas fabricantes de máquinas e equipamentos e empresas de manutenção industrial de máquinas e equipamentos. A escolha da empresa foi em função de sua atuação ativa nas estratégias de marketing e também pela facilidade de acesso às respostas reais.

"O estudo de caso é caracterizado pelo estudo profundo e exaustivo de um ou de poucos objetos, de maneira a permitir o seu conhecimento amplo e detalhado, tarefa praticamente impossível mediante os outros tipos de delineamentos considerados." (GIL, 2008, p. 58). 


\subsection{Procedimentos de coleta de dados}

Para tanto foi elaborada um questionário semi estruturado, pela Plataforma Google Drive, com 21 perguntas abertas e fechadas.

\subsection{Procedimentos de análise de dados}

Qual o ramo de atuação da empresa?

Porte da Empresa?

Mercados de Atuação?

Principais formas de divulgação e vendas?

Qual a forma de relacionamento com o mercado?

$\square$ Para a empresa, em ações de marketing quais os tipos de estratégias são mais utilizadas?

A empresa usa o marketing digital em suas ações de marketing?

Se a resposta anterior for sim, quais os meios você utiliza?

Nas ações de marketing da empresa, considera-se a utilização do inbound marketing?

Se sim, há quanto tempo a empresa utiliza o inbound marketing em ações de marketing?

Com qual frequência a empresa utiliza o inbound marketing nas ações de marketing da empresa?

O Inbound Marketing pode ser usado em meio online, estratégias em mídias sociais são um exemplo. Sobre as ações de inbound, com qual frequência são realizadas em meios online?

O Inbound Marketing pode ser usado em meio online, estratégias em mídias sociais são um exemplo. Sobre as ações de inbound, com qual frequência são realizadas em meios offline? Sempre

Para a empresa qual a importância de estratégias do inbound nas ações de marketing?

Quais mídias sociais (online) a empresa utiliza para a aplicação de inbound marketing?

Qual o nível de utilização da empresa na aplicação do inbound marketing?

Quanto a empresa investe financeiramente em estratégias de inbound marketing?

Quais as 3 principais dificuldades encontradas pela empresa durante a aplicação de ações inbound marketing?

A empresa contribui para a formação de seus profissionais em inbound marketing?

Em sua opinião quais as competências necessárias para um profissional que trabalha com marketing digital?

\section{RESULTADOS}

1. Qual o ramo de atuação da empresa? Indústria metalúrgica com produção verticalizada, certificada ISO9001. Desde 2003 a empresa trabalha baseado no planejamento estratégico, com indi- 
cadores como metas fabril e comercial para cumprir, participação nos lucros, 5S, ISO, que auxiliam nas tomadas de decisão e tem aprimorado constantemente. Nunca se preocupou em descrever sua missão e visão para os colaboradores internos, porém, elaborou um planejamento consistente afim de definir metas e objetivos alcançáveis e de longo prazo, tinha que agir senão fechava as portas e havia apenas uma saída: com muito planejamento e cobrança, romper o ciclo de inércia e conformismo, aplicando um "choque" geral, especialmente nos profissionais de vendas. Definiu-se um detalhado planejamento comercial e de marketing, coordenado pela consultoria e elaborado pelos gerentes e diretores da empresa. A marca tem boa reputação e tradição. Os produtos são de alta qualidade e a agilidade no atendimento da empresa satisfaz os clientes. Os clientes enxergam como uma empresa ética e séria. Cumpre o que promete e está sempre buscando melhorias. Através de ações de fidelização e relacionamento os clientes apontam um nível altíssimo de satisfação entre 95\% e 99\% em pesquisa de satisfação realizada com os clientes ativos e inativos.

2. Porte da Empresa: Empresa com mais de 110 funcionários, porte médio, que mesmo com as crises no País tem mantido seu número de funcionários, faturamento e fidelização de seus clientes.

3. Mercado de Atuação: líder no mercado de rolamentos industriais com mais de $80 \%$ do mercado brasileiro; Exporta 30\% do seu faturamento para EUA, Países da América do Sul, Canadá, entre outros.

\section{Principais formas de divulgação e vendas:}

- Catálogos, Folders, Banners.

- E-mail marketing (em datas comemorativas, promoções, etc)

- Mobile Marketing (SMS; Whatsapp; Skype; APP)

- Publicidade online (links patrocinados, banners, etc)

- Mídias Sociais (Facebook, Linkedin, , Youtube, Vímeo)

- Website responsivo com catálogo de produtos eletrônico.

- Revistas segmentadas do setor de Papel e Celulose; Mineração; Máquinas e Equipamentos, etc.

5. Qual a forma de relacionamento com o mercado? B2B - Business to Business (a empresa se relaciona com outras empresas, que muitas vezes, são intermediários); As vendas diretas são para montadores de máquinas/ equipamentos industriais e representa $25 \%$ das vendas totais, porém, evita a venda direta para o cliente final, dando preferência sempre para os intermediários. Já as vendas indiretas representam $75 \%$ e são direcionadas para canais de distribuição em todo o Brasil, através de distribuidores localizados na região Sudeste e o restante são vendas para OEM e empresas de manutenção de máquinas industriais. Hoje a empresa tem uma carteira de mais de 3500 clientes, com vendas realizadas pelo call center (vendas realizadas $100 \%$ por telemarketing, através de 4 vendedores internos qualificados para atendimento direcionado ao distribuidor), por telefone, e-mail, skype (antes se utilizava o fax), e atualmente através de whatsapp. A empresa possui representantes comerciais que tem a função apenas de visitar os clientes e suprir suas necessidades in loco, porém, os pedidos são 
tirados pelo call center e as comissões repassadas para os representantes da área. Para as visitas técnicas, conta com 2 com engenheiros de aplicação de produto e comercial, que dá treinamentos e faz visitas constantes nos clientes estratégicos, bem como acompanha as promoções no Ponto de Venda.

6. Para a empresa, em ações de marketing qual o tipo de estratégia é mais utilizado? Marketing Institucional através de mídias impressas e digitais, como anúncios em revistas e jornais segmentados; participação em feiras de mineração; treinamentos para clientes através de vídeos técnicos e institucional, manuais de instrução, aplicativo que ajuda fazer montagem e desmontagem de máquinas (APP); catálogo eletrônico de produtos. Marketing de relacionamento Direto, através de mala direta, telemarketing, e-mail marketing em datas comemorativas, Newsletters, etc.

\section{A empresa usa o marketing digital em suas ações de marketing? Sim.}

8. Se a resposta anterior for sim, quais os meios você utiliza?

- Mídia Online: compreende os meios de comunicação que se utilizam da linguagem binária da informática.

- Search Engine Optimization (SEO): traduzido como Otimização de Motores de Busca, trata-se de um conjunto de técnicas que possuem o objetivo de melhorar o posicionamento de páginas nos mecanismos de buscas online, dessa forma, quando o usuário realiza uma pesquisa pela palavra-chave, o SEO faz com que uma ou algumas páginas do seu website sejam encontradas e apareçam, entre os primeiros resultados das buscas orgânicas, ou seja, excluindo-se os anúncios pagos.

- Social Mídia (Redes Sociais): definida como um conjunto de dinâmicas que permite a criação de conteúdo, difusão e trocas de informações, dentro de grupos sociais em plataformas online, ou seja, a chamada rede social. Estas ações são produzidas pela interação de seus usuários através da propagação de informações, compartilhamento de conteúdo, e demais mobilizações sociais realizadas em meio eletrônico.

- Marketing de Conteúdo: trata-se de um conjunto de ações em marketing ou negócios que visa criação e distribuição de conteúdo para atrair, conquistar e envolver o público-alvo com a sua marca, sempre com a intenção de gerar lucro.

- Inbound Marketing: são ações estratégicas de marketing tendo o objetivo fazer com que o cliente voluntariamente, ao buscar informações importantes ou respostas as suas perguntas, seja capaz de encontrar a marca por meio de mecanismos de busca online ou offline.

- Web Analytics (Web Análise): consiste no monitoramento de ações da marca na internet através da coleta de dados estatísticos, medição e análise quantitativa, para otimizar os Websites e as iniciativas de marketing na $\mathrm{Web}$.

9. Nas ações de marketing da empresa, considera-se a utilização do inbound marketing? Sim

10. Se sim, há quanto tempo a empresa utiliza o inbound marketing em ações de marketing? Desde 2013.

11. Com qual frequência a empresa utiliza o inbound marketing nas ações de marketing da 
empresa? Sempre

12. O Inbound Marketing pode ser usado em meio online, estratégias em mídias sociais são um exemplo. Sobre as ações de inbound, com qual frequência são realizadas em meios online? Sempre

13. O Inbound Marketing pode ser usado em meio online, estratégias em mídias sociais são um exemplo. Sobre as ações de inbound, com qual frequência são realizadas em meios offline? Sempre

14. Para a empresa qual a importância de estratégias do inbound nas ações de marketing? Muito importante, pois queremos inovar sempre para atender nossos clientes.

16. Quais mídias sociais (online) a empresa utiliza para a aplicação de inbound marketing?

- Facebook

- Linkedin

- Google +

- Youtube

- Vímeo

17. Qual o nível de utilização da empresa na aplicação do inbound marketing? A nossa melhor mídia é o Google Adwords. Segundo dados do Google Analytics (junho/18), as campanhas do Google Adwords foram a segunda fonte de tráfego para o site da empresa, perdendo somente para a busca orgânica. Temos uma assessoria mensal que nos auxilia afim de melhorar o desempenho no Google Adwords, fornecendo relatórios que contém as campanhas, taxas de conversões, grupos de anúncios, conversões por dispositivo, cliques por gênero, cliques por localização, relatório por palavras-chave, etc, conforme um dos dados do relatório mensal (junho/18), da Figura 1 abaixo:

Figura 1 - Visão Geral Google Adwrods

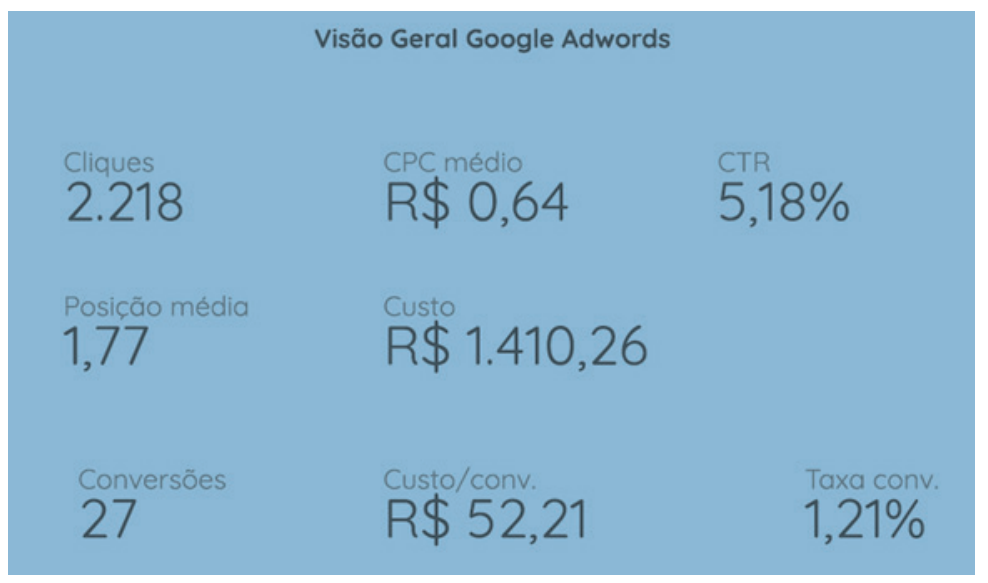

Fonte: datastudio.google.com. 
18. Quanto a empresa investe financeiramente em estratégias de inbound marketing? O valor aproximado de investimento mensal no Google Adwords é de $\mathrm{R} \$ 1.400,00$. No entanto, no Plano de Marketing, investe $1 \%$ do seu faturamento anual.

19. Quais as 3 principais dificuldades encontradas pela empresa durante a aplicação de ações inbound marketing? Falta de pessoas capacitadas no departamento de Marketing (composto apenas por 1 consultora de marketing, o restante são todos de vendas internas); Falta de tempo para criar conteúdos interessantes para cada público, como por exemplo, $A P P$ e $E$-Books. Falta de investimento em Comércio Eletrônico; Falta de confiança nas novas Mídias, pois as redes sociais e whatsapp são focadas em pessoas físicas e não jurídicas. Falta de monitoramento dos dados, como por exemplo, relatórios do Google Analytics e das redes sociais, também acompanhamento dos leads (prospects) do mercado externo. Muita informação e abordagens aos clientes, podem prejudicar o relacionamento.

20. A empresa contribui para a formação de seus profissionais em inbound marketing? Sim. A empresa investe anualmente para que o pessoal de vendas e marketing façam cursos de atualização.

21. Em sua opinião quais as competências necessárias para um profissional que trabalha com marketing digital? Estar sempre conectado com as tendências e mudanças de hábitos do mercado. Conhecer bem as necessidades e desejos de seus clientes, tanto do mercado interno como externo. Estar sempre atento às novas estratégias de comunicação e relacionamento do mercado. Como ele compra? O que compra? Quando compra? De quem está comprando? Porque compra? Agilidade nas respostas; Ter qualidade na comunicação com os clientes, fazendo com que toda a empresa seja qualidade total e com foco na satisfação do cliente.

\section{DISCUSSÕES}

Percebe-se nesse contexto, que a empresa possui um estilo arrojado de vendas, talvez o número de atendentes não seja suficiente para expansão das vendas de uma forma mais intensa, porém, os vendedores internos já possuem um conhecimento personalizado dos seus clientes.

\section{CONCLUSÕES}

O estudo mostrou que a empresa pesquisada está atenta a essas mudanças, pois utiliza o inbound marketing em suas ações estratégicas de marketing com frequência, já há oito anos, sendo o Google e as redes sociais mais utilizadas para sua vinculação. $O$ estudo também mostrou que o marketing tradicional e inbound marketing aplicado em meios off-line, mantém se em uso.

A pesquisa também revelou que, as principais dificuldades na aplicação do inbound marketing citadas foram: a geração de conteúdo relevante de qualidade; as rápidas mudanças e a grande complexidade envolvida em cada mercado específico; a falta de recursos humanos e tecnológicos que afetam 
as áreas de marketing das empresas e a qualificação limitada dos profissionais da área; e a finalização da venda (objetivo principal).

Esses dados revelam que as empresas devem investir cada vez mais em ações de mídias sociais e estratégias de SEO, facilitadas por ferramentas e técnicas online, como mobile marketing, realidade aumentada, e-commerce, m-commerce, redes sociais, e-mail marketing, SMS, Bluetooth, Tv digital, Web digital, etc. imprescindíveis para que entendam a influência que a internet está trazendo na vida das pessoas e o que está ocorrendo no mercado, mantendo-se atualizada.

\section{REFERÊNCIAS}

AGUIAR, K.; BASTOS, F. Inbound Marketing para o varejo: a chave para atração e retenção de clientes. Revista do Centro Universitário Newton Paiva, Belo Horizonte, n. 13, 2016.

AMERICAN MARKETING ASSOCIATION. Dictionary: Database Marketing. Disponível em: https://www.ama.org. Acesso em: 15 maio. 2018.

ASSAD, N. Marketing de conteúdo: como fazer sua empresa decolar no meio digital. 1. ed. São Paulo: Atlas, 2016, p. 12.

ENDEAVOR. Marketing Digital para empreendedores. Disponível em: https://www.endeavor. org.br/novo-ebook-gratuito-marketing-digital-para-empreendedores/. Acesso em: 04 de abr. de 2018.

GIL, A. C. Método de Pesquisas Sociais. 6. ed. São Paulo: Atlas, 2008.

HUBSPOT. A história por trás de nossa história. Disponível em: https://br.hubspot.com/internet-marketing-company. Acesso em: 07 de abr. de 2018.

HUBSPOT. The Inbound Methodology. Disponível em: https://www.hubspot.com/inbound-marketing. Acesso em: 07 de abr. de 2018.

JARA, A. J.; PARRA, M. C.; SKARMETA, A. F. Marketing 4.0: A new value added to the Marketing through the Internet of Things. In: INTERNATIONAL CONFERENCE ON INNOVATIVE MOBILE AND INTERNET SERVICES IN UBIQUITOUS COMPUTING, 6, 2012. Palermo. Anais... Palermo: IEEE, 2012. p. 852-857.

KOTLER, P. Administração de Marketing. 10. ed. São Paulo: Prentice Hall, 2000. 
KOTLER, P; KARTAJAYA, H; SETIAWAN, I. Marketing 3.0: As forças que estão definindo o novo marketing centrado no ser humano. Rio de Janeiro: Elsevier, 2010.

OLIVEIRA, M. B. C. F. Análise do impacto da implementação de uma estratégia de inbound marketing na geração de LEADS: estudo de caso das empresas Voxtron e Youlead. Dissertação. 108f. (Mestrado em Comunicação nas Organizações) - Escola de Comunicação, Arquitetura, Artes e Tecnologias de Informação, Universidade Lusófona de Humanidades e Tecnologias, Lisboa, 2015.

PERNISA JR, C. Mídia digital. Revista Lumina, v. 4, n. 2, p. 175-186, 2001.

PIEDRAHITA, F. E. P. Inbound Marketing y su incidência en el posicionamento de la marca Great Wall de Ambacar Cía. Ltda. de la Ciudad de Ambato. 2015. 125 f. Trabalho de Conclusão de Curso (Engenharia em Marketing e Gestão de Negócios) - Facultad de Ciencias Administrativas, Universidad Técnica de Ambato, Ambato/Equador, 2015.

PULIZZI, J. Marketing de Conteúdo Épico. 1. ed. São Paulo: DVS Editora, 2016.

RECUERO, R. Mídia x rede social. Disponível em: http://www.raquelrecuero.com/arquivos/midia_x_rede_social.html. Acesso em: 06 abr. 2018.

RICOTA, F. O que é SEO? 2007. Disponível em: https://www.agenciamestre.com/seo/o-que-e-seo. Acesso em 05 de abril. 2018.

SFREDO, A. R. Inbound marketing como estratégia de relacionamento entre cliente e empresa: Lush Cosmetics. 2017. 27 f. Trabalho de Conclusão de Curso (Especialização em Marketing Empresarial) - Centro de Pesquisa e Pós-Graduação em Administração, Universidade Federal do Paraná, Curitiba, 2017.

TELMA, M. F. P. O uso das ferramentas de web analytics no processo de inteligência competitiva das organizações. 2011. 104f. Dissertação (Mestrado em Ciência, Gestão e Tecnologia da Informação) - Programa de Pós-Graduação em Gestão da Informação, Universidade Federal do Paraná, Curitiba, 2011.

TURCHI, S. Estratégias de marketing digital e e-commerce. 2. Ed. São Paulo: Atlas, 2018.

VAZ, C. A. Google Marketing: o guia definitivo do marketing digital. 2. ed. São Paulo: Novatec Editora, 2010. 85 p. 